\title{
WHY ONE'S PRACTICAL REASONS ARE NOT JUST ONE'S OWN PRIVATE AFFAIR*
}

\author{
Stefano Bertea \\ University of Leicester
}

\section{Introduction}

Dr S. Cholar, who is a lecturer at the Lowerlands University - a publicly funded institution - decides to join the one-month strike, called by the union she is member of, against the decision of Mr T. Ory, the recently elected Prime Minister of the ambitious State of Little Island, to implement a widespread a programme of radical cuts meaning, among other things, that all the publicly funded higher education institutions in the country will be privatised. Shortly before the strike is scheduled to begin, Dr S. Cholar is confronted by Mr S. Poiled, the president of the local student society, who claims that Dr S. Cholar (and her colleagues) should not go on strike, since that action is not in the best interest of the Lowerlands University students. Mr S. Poiled holds that, as a result of Dr S. Cholar's conduct, the students of Lowerlands University are going to miss crucial classes and, consequently, are likely to get lower grades at the end of the year examination. This, in turn, will decrease their chances to find a qualified job once their university course has been completed. Dr S. Cholar's strike action, accordingly, should be called off, since it is going to impact negatively on the value that the degree of the Lowerlands University students will have in the competitive job market of Little Island. To this argument Dr S. Cholar replies that the strike is the only means she and her colleagues have to make Mr T. Ory rethink his programme of savage cuts in the higher education sector. She hopes that the strike action will have the effect to block Mr T. Ory's privatisation plan by so decisively contributing to the preservation of the public status of the higher education institutions in Little Island. This change in the government policy will then benefit present and future generations of university students, since only public institutions can secure a system of education

* This research was supported by a Marie Curie Intra European Fellowship within the $7^{\text {th }}$ European Community Framework Programme. I would like to express my indebtedness to Jaap Hage for a series of stimulating conversations on this topic, as well as for his comments on earlier drafts of this work. Needless to say, the responsibility for the views expressed herein, as well as for any errors of form or content, rests solely with me. 
that is both financially accessible and fair to every party involved. On this basis, Dr S. Cholar believes that she should join the strike, instead of acting as Mr S. Poiled suggests. In their exchange, Dr S. Cholar and Mr S. Poiled not only put forward (contrasting) claims but also they appeal to (different sets of) reasons to support their preferred course of action. As we look at this disagreement, are we legitimated to claim that Dr S. Cholar gives (genuine) reasons in support of her decision to strike against $\mathrm{Mr} \mathrm{T}$. Ory's project to privatise the academic institutions of Little Island, despite the fact that Mr S. Poiled cannot see them as valid grounds, or should we instead conclude that in the exchange under consideration not only Dr S. Cholar fails to convince Mr S. Poiled but also she confines herself to express a personal practical preference and to voice a private concern by thus offering no reason Mr S. Poiled should regard as (presumptively) justifying her choice? To state the question in more general terms, is someone's else failure to acknowledge the value of the reasons an agent supplies in support of her action due to the fact that reasons for action constitutively are personal, or private, statements that others thinking faultlessly may on occasion legitimately refuse to treat as genuine (prima facie) justifications for the relevant undertaking?

Crucially, once it is framed in general terms, the question just introduced invites us to and engage with the ongoing debate among those who defend and those who criticise the thesis of the publicity of practical reasons. ${ }^{1}$ The issue at stake in that debate is whether or not practical reasons are necessarily shared standards. What is meant here by a "shared standard" is not just a standard that happens to be other-regarding - to the effect that in the presence of a shared standard someone can legitimately take the interests of other subjects as reasons for acting in a certain way. A standard is shared in the relevant sense only if it has to be upheld by others and is thus taken as an (at least presumptive) justification not only by the agent to whom that standard directly applies but by others too (including the others who may not approve of the conduct carried out by one acting on those reasons). Insofar as practical reasons are conceived as private standards of conduct, as opposed to public standards (and so shared standards in the specific sense just introduced), one's reasons have no impact on what others are legitimated, or even ought, to do. Accordingly, other subjects may be completely indifferent to, and legitimately fail to acknowledge the validity of, the reasons a particular agent provides in support of her conduct.

In this paper I intend to take a stance in the debate concerning the private or public quality of practical reasons by arguing that - far from amounting to statements of personal concerns - practical reasons are inherently public, or constitutively shared, standards. Accordingly, an agent's reasons are not concerns that only the agent takes as grounded, whereas other individuals may legitimately fail to recognise them. Inso-

\footnotetext{
${ }^{1}$ Among the major contributions to this debate one can list Nagel (1970, 90-8; 1986, 164-88), Darwall (1983, 117-67), Parfit (1984, 142-3), Pettit (1987), McNaughton and Rawling (1991; 1995), Korsgaard (1996a, 275-310; 1996b, 132-45; 2009, 191-206), O’Day (1998), Norman (2000), Le Bar (2001), Gert (2002), Willigenburg (2002), and Wallace (2009).
} 
far as one has a reason for action, that action is supported by a statement that others cannot refrain from treating as a sound basis for action without misunderstanding the predicament at stake. The view I defend here is, therefore, that one's practical reasons are essentially public considerations in a specific sense, namely, they ought to be recognised as valuable justifications for action not only by the agent but by anyone else, including those who may have different, or even conflicting, interests. Related, idiosyncratic preferences, private motives, personal interests and the like cannot be regarded as practical reasons, since, no consideration can be qualified as a practical reason unless it is intersubjectively acknowledgeable as a meaningful supporting ground of action and so it makes normative claims a generality of subjects, as opposed to just the agent, will have to regard as (at least presumptively and defeasibly) valid.

As I will illustrate in some detail, the sense of publicity of practical reasons I argue for in this paper occupies a middle ground between the two fundamental meanings of publicity of reasons defended in the literature. For one thing, the thesis I champion in this work is stronger than the claim that practical reasons are public insofar as they are intelligible by anyone thinking clearly; for another, my view is weaker than the claim, supported by the most radical advocates of the thesis of the public quality of reasons, that practical reasons are necessarily shared by those directly or indirectly concerned by them. In order to systematically argue for my variant of the public character of practical reasons - a variant that I acknowledge to be potentially controversial as it can be attacked not only by those who defend the inherently private quality of reasons but also by those who theorise different senses of the publicity of reasons - I will have first to introduce the fundamentals of the debate concerned with whether practical reasons are by nature public standards or, instead, they are statements that merely summarise private and personal concerns. In my introductory engagement with the current debate, which is carried out in Section 2, I will embark in more than a mapping exercise: far from merely describing, or simply reconstructing, positions others have argued for, in this part of my study I intend to construct an original conceptual framework that will enable the reader to appreciate both relevance and direction of my argument. Once the foundations of the argument I offer are thus established I will pass, in Section 3, to defend my own understanding of the public quality of practical reasons.

\section{Are Practical Reasons Public or Private Standards of Action?}

In the literature two different views of (the character of) practical reasons have been defended. ${ }^{2}$ The main purpose of this section is to characterise those views by

\footnotetext{
${ }^{2}$ The distinction has been dealt with under different names in the literature. Nagel (1970, 908) discusses it by introducing a distinction between "subjective" reasons and "objective" reasons. This dichotomy is later replaced by the distinction between "agent-relative" reasons and "agent-neutral” reasons (Nagel 1986). Postema (1998) opts, instead, for a formulation of the distinction that is framed in deliberator-centred terms, when he distinguishes between "deliberator relative" reasons, and "deliberator neutral" reasons. An additional formulation is given by Korsgaard (1996b, 134-6; 2009, 191-2), who introduces the "private” versus "public" rea-
} 
preliminarily revisiting the traditional framework within which the debate concerning the quality of practical reasons is carried out before moving to offer a revisionary reinterpretation of the stances defended by those who engage in the discussion about the nature of practical reasons. This means that my critical approach to the current controversies concerning the quality - public or private - of practical reasons will be selective and partial: here one should not expect to find an exhaustive account of the various positions that have been argued for by the participants in the debate.

\subsection{The Privacy Thesis}

The thesis of the private nature of reasons - henceforth, the privacy thesis - can be summarised in the claim that practical reasons individuate inherently private, or agent-relative, considerations. This conception relativizes the notion of a practical reason to the agent it is a reason for. A practical reason, in this view, is not an essentially shared standard; accordingly, the normative force of a practical reason does not extend across different subjects. This means that, if a consideration is a reason for an agent to perform some conduct, then it is not necessarily the case that it will have normative force for other individuals as well. The practical reasons an agent endorses, in this conception, have no necessary bearing, and make no claim, on others. A reason can occasionally be acknowledged as being indirectly authoritative by more than just one individual, to be sure; but this is merely a contingent possibility and so may or may not occur.

The basic idea underlying the privacy thesis can also be expressed by saying that the notion of a reason has a built-in subjective dimension: where there is a reason for a subject to act in a given way, others are not necessarily justified, or even bound, to take that reason into account and shape their conduct accordingly. Since practical reasons are essentially subject-related, no one is obligated to consider the reasons of others when deciding what they ought to do. To use a figurative language, the privacy thesis defines the domain delimited by practical reasons as one's own "backyard”, or a fenced-off area, which is possibly owned and inhabited by a single agent, as opposed to a shared space that, like a town square, is occupied, or at least can be occupied, by a potentially indeterminate number of individuals all of whom share and recognise the same reasons.

The privacy thesis can be considered the dominant view today. ${ }^{3}$ Among philosophers it is largely believed that practical reasons are not essentially shared. Whilst it

sons dichotomy. The different formulations do not overlap precisely. For a critical discussion of the various distinctions introduced so far in the philosophical literature one can refer to Ridge (2005).

${ }^{3}$ See, for instance, Sturgeon (1974), Williams (1981), Parfit (1984, 142-4), Mack (1989; 1998), Dreier (1996), Le Bar (2001) and Gert (2002). An original position, which I tend to classify as a defence of the privacy thesis is theorised in Hage (forthcoming, "Facts and Meaning"; especially when read in combination with: Hage, forthcoming, “The Justification of Value Judgement”). 
is certainly acknowledged that there may be cases and circumstances in which a consideration justifying the performance of a certain action on the part of a specific agent will also be regarded as justifying some undertaking by other subjects, this is not a necessity - as one does not have to concede that the reasons given by others provide normative power for one's own action - but rather a mere possibility - as one may concede that sometimes the reasons of others have normative power for one's action too. ${ }^{4}$ The upshot of this approach is that there is no conceptual obstacle - no obstacle, that is, inscribed into the concept of a practical reason - to taking a certain standard as providing adequate ground for an agent's acting in a certain way while regarding it as failing to perform a normative function in relation to other individuals.

From the conceptual point of view, in other words, there is nothing amiss in a scenario in which (a) an agent motivates or justifies her action by appealing to considerations she personally deems as valuable and yet (b) those considerations are seen by other subjects as unmotivated or unjustified, namely, they are regarded as having no intersubjective or interpersonal value. From this view, then, an agent is perfectly entitled to prioritise her personal projects, even idiosyncratic ones, over projects whose value is generally acknowledged, whilst at the same time not being viewed as acting for no reason at all, or contrary to the demands of practical reasons. ${ }^{5}$ This means that no agent has an obligation to recognise the reasons of others, since those reasons have to be held as purely personal, or even possibly idiosyncratic, and so not essentially shareable by (or even not inherently communicable to) other agents. In sum, those who support the privacy thesis treat practical reasons as agent-relative considerations: that is, considerations that do not necessarily extend their normative effects beyond the agent to which they primarily and directly apply.

\subsection{The Publicity Thesis}

The objection to these claims is that they are based on a fundamental mistake about the nature of a practical reason. The picture of a practical reason as an inherently personal, or private, standard, it is counter argued, rests on a misunderstanding of what a practical reason is. Far from reflecting personal concerns practical reasons are essentially public standards: their normative significance necessarily extends beyond the agent who has them or is primarily concerned with them - I will call this the thesis of the publicity of reasons, or publicity thesis for short. A practical reason, for those who embrace the publicity thesis, is at least partly indifferent to the distinction

\footnotetext{
${ }^{4}$ For a defence of these claims see, amongst others, Gert (2002).

${ }^{5}$ And in fact, at least in a possible version of the privacy thesis - defended, for instance, in Williams (1981) - we deny the privacy of (certain) reasons only at the cost of depriving agents of their specificity and individuality. For, unless we allow for the possibility that an individual's action is guided by her own distinctively personal projects and commitments - projects and commitments that are not of necessity shared by others - we end up denying the very individuality of an agent by not granting her sufficient freedom to design her own life.
} 
between agents and so a consideration supporting the relevant conduct that produces effects not only on a specific agent but also on any other subject. Reasons, in other words, are in their essence agent-neutral, or impersonal, and so should be constructed as constitutively relational and interpersonal. Accordingly, a practical reason should be characterised as an essentially shared standard that directly governs and, in certain cases, makes obligatory not only an action of the agent who has originally deliberated about it, but also related actions of different individuals. On this view, thus, practical reasons are sources of justifications that potentially apply to courses of conduct carried out by any agent.

To rephrase the idea, the main insight underpinning the publicity thesis is that, unless a certain consideration supports a given conduct from the point of view of any agent, it is not a genuine practical reason, namely, it should not be taken to be a reason proper and should be regarded instead as being a bogus reason. This is to say, being public is a defining trait of a practical reason and so an essential condition for something to count as a reason (in the true sense). As one critic of the publicity thesis puts it, for those who accept the thesis it is not possible to "make just anything a reason simply by calling it a reason", since "there needs to be some criterion to distinguish between correct and incorrect applications of [the concept of a reason]” (LeBar 2001, 263). Accordingly, some kinds of considerations - precisely, the considerations whose normative effect is confined to the agent who has them - are constitutively excluded from the qualification of "practical reasons"; they are rather to be qualified as "counterfeit practical reasons", or statements that provide seemingly practical support. Related, the public quality makes a practical reason discontinuous with, and irreducible to, a personal state a particular agent may have. Whilst the latter is essentially private and so can in principle back the action performed by one agent only, without having to be regarded as authoritative by others, a practical reason has a built-in intersubjective element and so its force is to be conceded by any agent who encounters it. This means that it is a conceptual impossibility for a reason to have, say, an obligatory force in relation to one agent while having no force in relation to other agents. ${ }^{6}$

The thesis that a practical reason is, by its very nature, a consideration that can be publicly assessed and has force anyone thinking clearly is bound to recognise has, in turn, been interpreted in three distinct ways. In the most basic, minimal and least demanding sense the publicity thesis refers to a situation where reasons are defined as considerations that are mutually intelligible, understandable and communicable to different subjects. ${ }^{7}$ No reason can be said to be a private consideration in the sense of

\footnotetext{
${ }^{6}$ To resort to the figurative language introduced above, the publicity thesis depicts a practical reason as a town-square-like notion: a practical reason does not describe a fenced-off space, which is occupied by just one agent in the manner of a private owner; a practical reason individuates, by contrast, a domain inhabited by, and accessible to, a potentially indefinite number of individuals.
}

${ }^{7}$ This version of the publicity thesis is defended in Norman (2000). 
being a consideration that is inaccessible, or incommunicable, to other individuals. Anyone will have to regard a practical reason as a meaningful consideration that applies to the relevant context and justifies the performance it supports. In this interpretation, publicity stands for intelligibility: a reason is a consideration that is generally viewed as a statement characterising a certain state of affairs as desirable in a universally understandable way. In that respect, a practical reason can be considered a public standard of meaningfulness and intelligibility, as opposed to an idiosyncratic standard that only some agents, or even just one agent, may make sense of.

Alternatively the publicity thesis has been interpreted as meaning that a reason is an objective ground on which anyone has to act. ${ }^{8}$ In this objective sense, publicity stands for actual sharing: a consideration that grounds an agent's performance simultaneously supplies the backing to other subjects for either performing the action supported by the original consideration or non-hindering it. This way, a reason is claimed to be completely independent of an agent's perspective: publicity is taken to be the equivalent of impersonality, or perspectivelessness. This interpretation of the publicity thesis is conceptually associated with the possibility of establishing the existence of objective values as well as attributing some objective value to the courses of conduct favoured by a practical reason. As long as the action one has a reason to perform can be regarded as having objective value, such an action is one that anyone will acknowledge to have to be performed. Accordingly, it is not the case that just one particular agent has reasons to carry out such a course of conduct. Being objectively good the relevant action should be carried out and, accordingly, its performance is something every agent ought to contribute to. An agent's reasons for action are, as a result, not just her own reasons but rather the reasons on which everyone else is legitimately expected to act, since they indicate ends, goals and purposes that every subject will have to regard as valuable and so recognise as worthy of being pursued.

A somewhat intermediate position between these two versions of the publicity thesis is defended in Christine Korsgaard's work (1996a; 1996b; 2009). Her defence of the publicity thesis is combined with Kantian constructivism in metaethics and is grounded in an original reading of Wittgenstein's private language argument, which, in her recent works, leads her to criticise the picture of human interaction as the interplay of private reasoners treating each other as mere instruments. ${ }^{9}$ The endorsement of metaethical constructivism prevents Korsgaard from aligning herself with the objectivist interpretation of the publicity thesis, though. For, from a constructivist view, an action can hardly be said to be objectively valuable, or good; it should instead be regarded at most as interpersonally, or intersubjectively so. This means that the value

\footnotetext{
${ }^{8}$ An argument supporting this version of the publicity thesis, although interpreted in a purely formal sense, is provided in Nagel (1970, 90-8); it was later qualified and radically revised in Nagel (1986, 164-88).

${ }^{9}$ The reference to Wittgenstein's private language argument can be found in Korsgaard (1996b, 136-45), whereas the notion of a "private reasoner" is introduced in Korsgaard (2009, 193-202).
} 
of the courses of conduct supported by a practical reason is not to be acknowledged, but is instead necessarily acknowledgeable, by all the individuals concerned. In this view, a practical reason arises - insofar as different subjects agree that the action a given consideration justifies is worthy of being pursued - neither just from the subjective perspective of a single individual, as the privacy thesis has it, nor from an impersonal standpoint, as the most demanding version of the publicity thesis has it, but from the intersubjective point of view. Thus, practical reasons can be understood as considerations that validate certain courses of conduct by making them appropriate in the light of values that hold interpersonally. Accordingly, this version frames publicity as a kind of shareability, which configures a practical reason as an essentially relational notion: to act for a reason is to act on a consideration whose normative force can inherently be shared with others. ${ }^{10}$ Publicity is thus associated to some interpersonal normative force: the normative force of a reason, qua a public standard, supervenes on the relationships of agents interacting one with another. This requires, in a nutshell, the reinterpretation of the idea of publicity as a kind of interpersonal authoritativeness, intersubjectivity, or singular-perspective neutrality.

\section{My Claim Introduced and Defended}

In this section I intend to champion (a variant of) the publicity thesis. With a view of doing so, I will first clarify in detail what the publicity thesis means to me - namely, how I suggest that it should be interpreted to be of greatest theoretical interest. I will then put forward an argument in its support. In this context, I should preliminary introduce two important caveats, which concern my reinterpretation of the controversy surrounding the private quality versus the public quality of practical reasons.

First, I reinterpret the claims made by the supporters of the privacy thesis and the advocates of the publicity thesis as claims referring to a substantive dimension of practical reasons - their force - as opposed to their formal, or syntactical, dimension. This makes my reconstruction of the divide between private reasons and public reasons somehow different from the understanding of that divide held by most participants of the debate. The opposition around which the debate has developed was originally framed by Thomas Nagel in terms of the form a practical reason takes. In Nagel's framework, a reason has to be regarded as essentially private - or, to use Nagel's (1970, 91) own terms, “subjective” - as long as it necessarily contains a "free-agent variable" in its formulation; a reason is to be conceived, instead, as essentially public - or “objective” in Nagel's terminology - as long as no "free-agent variable” appears of necessity in its statement. Accordingly, Nagel's opposition primarily concerns the syntax of practical reasons, that is, their formulation. ${ }^{11}$ By contrast, here I reinterpret

${ }^{10}$ On this notion see also Willigenburg (2002).

${ }^{11}$ A number of different theorists, including Nagel (1986, 164-88), Pettit (1987) and McNaughton and Rawling (1991; 1995) among others, have followed this tendency by focusing exclusively on the formal dimension of the distinction between private reasons and public rea- 
the debate between those who defend the privacy thesis and those who argue for the publicity thesis as a debate concerning the normative significance a practical reason constitutively has. I am interested, in other words, in whether or not the normative force a reason inherently has extends beyond the agent it directly applies to. Thus, the privacy thesis and publicity thesis are reinterpreted here as claims concerned not with the formulation, or syntactical appearance, of a practical reason, but rather with its authority and sphere of application. Therefore, the question addressed in this section is not: "should or should we not state a practical reason in a form that makes reference to the subject who directly acts on it?” Instead, the question is: “does a practical reason produce normative effects on other subjects besides the individual who directly acts on it?” Answering this question forces us to go beyond mere syntactical considerations and embark on a substantive treatment, the character of which is both semantic and pragmatic, of the notion of a practical reason.

The second caveat is that the normative effects of a practical reason I am concerned with are limited to its justificatory dimension. In the literature practical reasons are taken to have different meanings, for traditionally practical reasons have been grouped into three classes, depending on whether they are meant to serve as justifications, motivations, or explanations. ${ }^{12}$ By contrast, in what follows I will use "a practical reason" exclusively in the first meaning. In discussing the question of whether practical reasons have a private character or a public quality I consider practical reasons just in their justificatory role, namely, as statements that justify a course of action, and so state why we presumptively (and barring other contrary considerations that may outweigh or even exclude those statements) ought to act in one way and not in another way. Understood in this way, a reason is both practical and evaluative. It is practical in the sense that, as $\operatorname{Raz}(2008,184)$ frames the idea, it "gives a point or a purpose to one's action", which accordingly "is undertaken for the sake of or in pursuit of that point or purpose”. However, this is not just any point or purpose but

sons. A different concern, more in line with (albeit not exactly the same as) the one I am interested in, characterises other works, for example, Darwall (1983, 117-67), Korsgaard (1996a, 275-310; 1996b, 132-45; 2009, 191-206), Willigenburg (2002), and Wallace (2009).

${ }^{12}$ The three classes just mentioned are often reduced to two in the literature: there are (a) reasons that justify, referred to as justificatory, justifying, prescriptive, normative, or grounding reasons; and (b) reasons that explain, referred to as motivating or explanatory reasons. We can see this, for instance, in Dancy (2000b, 1-25). However, Alvarez (2010, 33-39) has compellingly argued that this twofold distinction arbitrarily conflates reasons that motivate with reasons that explain: this distinction is arbitrary because, as much as a motivating reason may go some way toward explaining someone's behaviour, it is but one ingredient in such an explanation, and so cannot be the explanation itself. True, the intent in either case is non-normative, but we should not thereby conclude that to show what motivates one to action is what explains that action, and motivating reasons, accordingly, ought to be kept distinct from explanatory reasons. This enriched threefold taxonomy of actions can also be found in Hieronymi (2011, 409-414). For an introduction to the various kinds of practical reasons, see Lenman (2010). 
one understood to have inherent value, and it is in this sense that a justificatory reason also carries evaluative meaning. The point - that is, the reason itself, or the ground for why we (ought to) behave as indicated - is understood to be right, proper, appropriate, or otherwise reasonable. So, even though the entire proposition may be open to criticism, it still carries with it a value judgment introducing that behaviour as right, proper, appropriate, or otherwise reasonable. A justificatory reason does so by offering a standard of evaluation and correctness, that is, a criterion in light of which we can judge a course of action as having those qualities (its being right, proper, appropriate, reasonable, and so on) and by virtue of which that course of action can be grounded, or rationalised, that is, shown to be the correct thing to do. This is to say that the argument I will offer in the rest of the essay is intended to show that practical reasons are public standards of justifications and thus publicity is a character that should be attributed to practical reasons in their justificatory function. A conceptual link can therefore be claimed to exist between the publicity of reasons and their interpersonal justificatory tenor. This means that a necessary connection arises between practical reasons, on the one hand, and intersubjective justification and legitimate criticism, on the other.

Importantly, the focus on the justificatory dimension of practical reasons contributes to markedly distinguish the version of the publicity thesis defended here from other views of that thesis, which apply the distinction between private reasons and public reasons to both the motivating force and the justificatory force of a practical reason..$^{13}$ In fact, the debate has largely been concerned with whether (a) a practical reason is an inherently personal consideration that in principle motivates only a specific agent to perform certain actions as well as justifies her to do so without necessarily playing the same motivating and justificatory role in relation to other individuals, or, conversely, whether (b) a practical reason is a consideration that is essentially shared, to the effect that it performs a motivating and justificatory function in relation to more than just one individual (the agent). By contrast, here I am interested in discussing whether or not a consideration, qua reason, essentially plays a justificatory role that anyone, as opposed to a single individual, is bound to acknowledge. The focus of the present discussion will, as a result, be more limited and confined when compared to the scope of the current debate on the publicity thesis.

Building on these premises, my understanding of the publicity thesis is loosely related to the interpretation of publicity as standing for shareability. Like those who frame publicity in terms of shareability, such as Korsgaard, I think that reasons are essentially public standards in a sense that is more demanding than, and thus goes beyond, mere intelligibility - a reason for action can be qualified as public only if it is more than merely understandable to others, to whom it can simply be conveyed in a meaningful way. ${ }^{14}$ The publicity of a reason certainly includes its mutual intel-

\footnotetext{
${ }^{13}$ Korsgaard's (1996a) treatment is paradigmatic in this sense.

${ }^{14}$ In that respect, my version of the publicity thesis can be located in the same ballpark as Korsgaard's. My variant, however, deviates from the one Korsgaard sets out to defend at least
} 
ligibility: my reason for a given action refers to a state that others can understand and make sense of, a state, that is, which is perspicuous to more individuals than just me. However, its intelligibility does not exhaust the public quality of a reason. A reason is public, in the sense in which I understand publicity, if it is shared in a deeper and denser sense. In my construction, publicity refers primarily to the state of a reason being of necessity respectable, or recognisable as a valuable consideration, by all the agents who may be confronted with it. This idea - publicity as potential recognition and appreciation across the boundaries between agents - includes the notion of intelligibility but goes beyond it. For publicity, when it is understood as I do, involves both mutual respectability and intersubjective acknowledgement of its value, neither of which is reducible to mere intelligibility. The thesis that reasons are essentially public, qua inherently recognisable, standards means that a consideration, in order to be regarded as a reason proper, must not just be understandable to other agents; it also has to be taken as making a normative claim on them. That is to say, the ideas of potential mutual recognition and acknowledgement accompany the very concept of a practical reason, which, accordingly, individuates an interpersonally binding justification, namely, a justification capable of making intersubjective claims. From which it follows that conceptually a practical reason not only produces normative effects on the performance of the agent who is directly concerned by it, but also it has normative implications for other subjects too. From this perspective, the normative influence of a practical reason transfers across agents. And this is a conceptual quality of a practical reason, namely, something that sets practical reasons apart from other kinds of (nonreason-like) considerations that count in favour of certain undertaking. ${ }^{15}$

The publicity thesis, as it is introduced and understood here, has a couple of important interrelated dimension. The first dimension is that my version of the publicity thesis does not require a practical reason to have the same justificatory effect on, or to bind equally, all the individuals to which it directly or indirectly applies. A reason may have diverse normative consequences for different subjects: a consideration that justifies acting in a certain way does not have to justify everyone else acting the same way. It may well be the case that a reason legitimises an agent's acting in one way whereas at the same time justifying that other subjects, far from having to do the same, simply have to find the agent's proposition valuable - namely, to regard it as a propo-

in one respect: it is only concerned with the justificatory dimension of practical reasons (by contrast, Korsgaard's claims concern the publicity of both motivating reasons and justificatory reasons). The focus of my approach to the question at stake, thus, is narrow(er than Korsgaard's). Which also means that the argument I offer in support of the publicity thesis cannot be used without significant adjustments and modifications to vindicate the conclusions about the public quality of practical reasons Korsgaard is committed to defend.

${ }^{15}$ This idea can be rephrased in Korsgaard's (1996a, 301; original emphasis) words as follows: a practical reason essentially makes normative claims on different agents by exerting its "authority over other people and yourself at other times"; which means that "to say that you have a reason is to say something relational". 
sition expressing a concerns others may well not fully endorse and yet cannot, while thinking faultlessly, treat as some agent's futile, or idiosyncratic, move. To express it in Wallace's (2009, 481-2) words, the defence of the publicity thesis is compatible with the statement that "my reasons can have normative significance for you, without it necessarily being the case that there is any interesting sense in which you and I both have reasons to do the same thing”. The variable normative effects that a consideration, qua practical reason, may turn out to have on different subjects may be due to different external factors, such as the different roles that subjects have in carrying out the course of action the relevant reason supports, or the different positions, even possibly in mutual conflict and competition, that they occupy in relation to the relevant undertaking, or the different contexts in which they operate, or the diverse capacities they possess. Given the variable circumstances an agent experiences it would be unreasonable to expect the publicity thesis to mean that a consideration, in order for it to be a reason, essentially requires every agent to perform the action it justifies. That is to say, the insight incorporated in the publicity thesis cannot, on pain of turning it into a patently untenable claim, be understood as referring to the fact that a reason, qua public standard, necessarily exacts the same performance from everyone. The publicity thesis should be interpreted, instead, as committing one to acknowledge the fact that a practical reason cannot hold for just one agent and, at the same time, be regarded as an arbitrary and non-shareable personal preference by (some) others. Namely, what the publicity thesis requires is that a practical reason does not have an impact on the normative position of just one agent while leaving (some) others unaffected or indifferent. Thus, conceding that other subjects may not have a reason to perform the conduct we have practical reasons to value cannot be seen as recanting the publicity thesis, provided that it is simultaneously acknowledged that those subjects also have to recognise the significance of the relevant conduct for us and so must regard our reasons as considerations any agent in our position would appeal to legitimately support the action we perform when acting upon those reasons. ${ }^{16}$ Publicity, in sum, should be taken to mean interpersonal normative significance, namely, to refer to the capacity of a consideration to count, although in different ways, for potentially any individual coming in contact with it and so to have justificatory influence across different agents. ${ }^{17}$ To put it succinctly, the normative force of a reason is public insofar as it conceptually transfers from agent to agent.

The second dimension of the publicity thesis, in the version I endorse, can be thus formulated: such thesis implies that practical reasons inherently command recognition on the part of anyone thinking faultlessly. This trait conceptually distinguishes a reason from a non-reason-like statement that is given in support of one's perfor-

\footnotetext{
${ }^{16}$ Remarks of a similar tenor can be found in Wallace (2009, 476-82).

${ }^{17}$ As Wallace $(2009,488)$ puts it, reasons are public in the sense that the very "same considerations that give you reasons to do X" do not lose their normative effect when they meet me, since they give me at least a presumptive "reason to refrain from meddling in your $\mathrm{X}$-ing".
} 
mance. On this basis, we are, then, in the position to distinguish between two conceptually distinct kinds of considerations providing practical support: reasons and nonreason-like statements (such as motives and expressions of personal preferences, for instance). In this context, let me introduce two fictional scenarios, which can help one to figure out the relevant difference between reasons and non-reasons, as my version of the publicity thesis leads one to understand them.

In the first scenario, on return from a business trip an old friend of mine, now a committed and workaholic broker, who has not taken a single break from work in the last ten years, meets me at the airport of Frankfurt, where I am waiting for a flight to Naples. Asked why I am heading for Naples, I reply that I have booked a ten-day holiday on the nearby Amalfi coast, where I am expected to enjoy sunny weather and delicious food - the trademarks of that region. In the second scenario, the broker and I meet (again) at the Frankfurt airport, but this time when asked why I am traveling to Naples I reply that I am doing so, since I only intend to buy a cask of ordinary German lager there - a brand of German lager that, as a matter of fact, is ordinarily available at the same price and in the same packaging at any local supermarket of the town I live in. My workaholic friend finds both "flying to Naples in order to take some holidays" (scenario 1) and "flying to Naples in order to buy a cask of lager available at any local supermarket” (scenario 2) less than commendable pieces of conduct. Yet, he (as well as anyone else finding both my journeys criticisable) categorise, and react to, the two practical options differently. Let me elaborate.

In the first scenario, the broker disapproves of my decision - taking a holiday whilst seeing the value (merely defeasible as it is) of that decision. If one considers taking a break from work, a stay on the Amalfi Coast is a sensible option, among countless others: everyone - even a workaholic - sees the rationale for my flying to Naples. On this basis, I can be claimed to have a reason for travelling to Naples. The justification supporting my journey is not one anybody will be prepared to uphold, to be sure. Indeed, a workaholic is perfectly entitled to think that I am wasting my time on something - holidays - that is not only unnecessary for my wellbeing - my workaholic friend has never been on holidays in the last decade and yet he is in a good shape - but also financially costly for both myself and the institution I work in - which has to do without my professional performance for ten days. On this ground, one's view may well be that the justification I provide in scenario 1 is weak and inconclusive by thus failing to vindicate my conduct all things considered. Despite all this, (even) a workaholic is expected not only to take the statement I gave in support of my (criticisable) choice as intelligible but also to recognise that statement as a potentially reasonable ground for flying to Naples. In other terms, my justification for travelling to Naples (a) is understandable (intelligibility of the ground I offer) and (b) makes perfect sense as a line of conduct one may find attractive (recognisability of the ground I offer).

Now, contrast all this with the way we (including the broker in the example given) can legitimately be expected to approach the second scenario. Anyone thinking clearly is likely to be puzzled by my reply to the broker in our second meeting at the 
airport. The sources of puzzlements do not reside in the fact that the statement I provide in support of my decision to fly to Naples is a consideration someone with different priorities and values would not be willing to act on (as it was the case in the first scenario). It should be located instead in the fact that buying a cask of lager ordinarily available next door does not count as a possible justification for flying to Naples. Accordingly, in the second scenario, one is (entitled to be) not only in disagreement with the agent but also puzzled by the conduct carried out. For, taken at its face value, my reply is not merely an arguably criticisable justification; it rather falls short of a justification altogether. Despite our best effort, we fail to see the grounds of someone's decision to travel so far away only to purchase something ordinary that is available at a local supermarket. It is not, in the second scenario, that an individual with different life plans and practical objectives disagree with me over the benefits of flying to Naples and taking a break from work, namely, on the reasons supporting my act; rather, on this occasion, without any fault on his part, the broker (and indeed anyone else too) is unable to recognise the ground I offer in support to my flying to Naples as a kind of justification - be it weak or strong. This is so, because in the second scenario, I do not give any reason that can be constructed as a sensible (even if criticisable) justification of my conduct. Instead, there I offer a non-reason-like statement supporting my practical move, that is, a statement that lacks any public quality, to the effect that even someone taking up my own distinctive perspective and sharing my enthusiasm about the Amalfi Coast is prevented from appreciating the value of my conduct. The statement I appealed to in my exchange with the broker in scenario 2, in other words, constitutes at most the formulation of a consideration that is intrinsically private and so a consideration others can legitimately refuse to recognise as valuable (even if they share my practical perspective). And this is why it is not a reason.

To generalise the case, in the first scenario I supply a statement in support of my move, which is public, namely, it is transparent to others who are thus able to both understand the grounds for action and recognise it as valuable (if only presumptively so). By contrast, in the second scenario the backing I offer is an expression of a merely private statement nobody else can appreciate and value as a ground for the conduct I perform. In this context, the comparative analysis of the two fictional scenarios introduced above serves to illustrate the role played by the public quality of a statement offered in support to one's performance. In such quality - publicity - resides the conceptual difference between a practical reason and a non-practical-reason-like statement supporting one's piece of conduct. Practical reasons do not (necessarily) provide sound and conclusive justifications for action, as the legitimate disagreement between me and the broker in scenario 1 attests. In fact, the possibility is always there that practical reasons are regarded by others as partial, or even weak, justification: they may well (turn out to) be statements that secure conclusive justifications for one's piece of conduct. Yet, practical reasons are conceptually different from non-practicalreason-like statements, since the former, even when they are weak or partial justifications, retain a public quality - public in the sense discussed above - whilst the latter 
instantiate concerns that may well be merely private, or even idiosyncratic, and so are intrinsically not shareable by others. To put it the other way round, whenever we are confronted with grounds for action expressing just a private concern we are not in the presence of a practical reason - not even a practical reason that can legitimately be considered weak or criticisable. Contrary to what the defendants of the privacy thesis claim, no such ground amounts to a practical reason, which by its constitution is a justification that is both intelligible to and susceptible of being appreciated (even if not necessarily upheld) by others - and in this sense is inherently public.

The preceding remarks should suffice to clarify the scope of my version of the publicity thesis. In the variant of the thesis I embrace it is conceptually true that whenever there is a reason $\mathrm{X}$ for an agent to act in some way other subjects cannot fail to acknowledge $X$ as a valuable consideration that contributes to, not necessarily in a decisive way, determine the resulting conduct both that agent and everyone else concerned ought to undertake. It is essential, however, not to read too much in the publicity thesis. For it does not entails, for instance, that if you have a reason to perform an action, then necessarily I have a reason to do the same - as we may have different priorities, life plans, institutional roles, and so on - or I have a reason to help you to do it - since your action may well, at least occasionally, stand in my way to achieving what I in turn (have a reason to) seek to achieve. My claim is rather that if you have a reason for acting in some fashion then I will have to take that reason into account when deliberating about my conduct or assessing the merits of yours, since that reason works (not just for you but) for me (and others) too as a presumptively intelligible and valuable consideration that justifies (at least prima facie) the course of conduct. At the same time, the version of the publicity thesis I set out to argue for in this paper is not trivially true - a stance even those who conceive of practical reason as private in quality would be ready to endorse. The variant of the publicity thesis defended here is indeed incompatible with the claim that one can legitimately be indifferent to another's reasons, to the effect that others are justified to pay no attention to the reasons supporting one behaviour and hence to treat those reasons are merely private considerations no one apart from the agent ought to be concerned with - which is the core of the privacy thesis. That my version of the publicity thesis is non-trivially true and can be set conceptually apart from the privacy thesis is attested by the fact that if an agent has a reason for acting in some way then everyone else is under the constraint to acknowledge the value - merely presumptive and limited in scope as it may (be regarded to) be - of the piece of conduct supported by the relevant reason. A reason, in that sense, differs in kind from a private concern that everyone apart from the agent can simply ignore, just neglect or thoughtlessly shrug off when reflecting about conduct. This characterisation configures practical reasons as public statements in the (limited and yet non-trivial) sense that anything we qualify as a practical reason occupies a shared space, namely, a space we all inhabit, we all ought to take care of and we all are responsible for. This conclusion is incompatible with the conception of practical reasons as private considerations - conception that is conceptually associ- 
ated with the privacy thesis. Hence, the non-triviality of my (modest) variant of the public quality of practical reasons.

So, how can this version of the publicity thesis be defended? And where does the essential publicity of a practical reason originate? Stated otherwise, why is it that a reason for acting cannot be conceptualised as an essentially personal consideration, the authority of which does not extend beyond the agent who has it? In order to answer these different formulations of the basic question concerning the fundamentally public quality of a practical reason one needs to look for a basis of the publicity thesis. This can, I believe, be found in, and derived from, the justificatory nature of a practical reason. Let me make this point in detail.

A practical reason is a consideration that counts in favour of one's conduct by justifying it. A practical justification, in turn, is an exercise of a certain kind: not every process aimed at supporting one's practical steps can be qualified as a justification. Justifying an action means showing that the action ought to be regarded as being of some value, as opposed to showing that the action is an undertaking the agent actually values and is willing to do. This statement highlights the fact that practical justifications inhabit the normative dimension of human experience: a practical justification is a process that conceptually unfolds in the normative territory. And, normativity, by its very essence, demarks a space that is public and relational, in so that normative standards are distinctively different from the criteria an agent sets for herself in independence of the interaction with others. Related, practical standards only become normative when others validate them.

This public character of normative standards emerges paradigmatically from Ludwig Wittgenstein's rule-following considerations, where the following question is posed: what does subjecting oneself to a rule mean ${ }^{18}$ Wittgenstein's contribution is particularly relevant here for two reasons. On the one hand, in Wittgenstein's work, a rule stands for any normative standard - which grants that what he claims about a rule and one's following a rule can be extended to, respectively, a practical reason, qua normative standard of justification, and one's acting on a practical reason. On the other hand, Wittgenstein explicitly defends the thesis that following a rule is a practice that is social in nature, by providing support to the claim that the normative domain has a public structure. From this claim one can infer that the fundamental notions defining what is normative (among which notions a practical reason figures prominently) are also public in essence.

Wittgenstein's statement that following a rule is an essentially social practice has attracted the attention of more than just one commentator. It is widely believed that Wittgenstein's view on the social nature of normative standards finds a particularly accurate reconstruction in the work of Gordon Baker and Peter Hacker, who take issue with the so-called "community view", the sceptical position originating in Saul

${ }^{18}$ These claims are mainly made in Wittgenstein (1968, §§ 185-242). 
Kripke's reading of Wittgenstein's rule-following remarks. ${ }^{19}$ The community view maintains that what counts as a correct application of a normative standard, when this is understood as a social process, is determined completely by what the community of users takes the standard to be. Baker and Hacker disagree with this interpretation, arguing, instead, that in Wittgenstein's thought the relation between a normative standard and its use, including its justificatory use, is grammatical, namely, internal to the formulation of the standard itself. ${ }^{20}$ This means that what is correct according to a normative standard does not consist in what a given community of users regards as correct. In Wittgenstein's philosophy, as they correctly notice, the concept of a normative standard differs from that of an empirical generalisation. Accordingly, the content of a normative standard does not coincide with the content most people think it has: the most widespread opinion among the members of a group is not the final court of appeal when it comes to determining the content of a normative standard they apply, nor can their general conduct be held up as the ultimate criterion for the correct use of the normative standard.

Baker's and Hacker's critique of the sceptical reading of Wittgenstein's remarks on normative standards - a critique based on the suggestion, which I take to be correct, that a normative standard is not entirely determined by its social use - should not, however, lead one to overlook the social structure of normativity and direct us towards the conception of a normative standard as a private notion. For that position is not compatible with Wittgenstein's treatment of normativity - a treatment that frames normative standards as standards that are conceptually dependent on their shared use and interpersonal appraisal, namely, as public standards. True, Wittgenstein claims that what a normative standard is does not depend exclusively on how it is used publicly; yet, far from framing a normative standard as an entirely private consideration Wittgenstein suggests that a normative standard incorporates a fundamental relational dimension.

The existence of an intrinsically relational component of normative standards emerges from several passages of Wittgenstein's work, especially where it is claimed that the directions a normative standard gives us depend on its regular use. ${ }^{21}$ The use referred to here is not the use a single agent believes to be appropriate for that norma-

${ }^{19}$ See in particular Baker and Hacker (1984, 1-55; 1985, 154-181). The sceptical view originates from the reading of Wittgenstein's rule following considerations put forward in Kripke (1982). The question that Kripke addressed was what makes the rules work, and the ensuing debate drew many philosophers. The essential contributions are from Blackburn (1984), McDowell (1984), McGinn (1984, $72-7$ and 168-75), Peacocke (1984), Wright (1984), Anscombe (1985) and Malcolm (1986, 154-81; 1989).

${ }^{20}$ See Baker and Hacker (1984, 18-21; 1985, 171-3).

${ }^{21}$ The direct connection between a normative standard and its use is pointed out in Wittgenstein's (1968, § 190) remark that "the kind of way we always use it, the way we are taught to use it” is the criterion for the way a normative standard is meant. See also Wittgenstein (1968, § 43). 
tive standard. By “use” Wittgenstein consistently means, in the context of his treatment of normative standards, a social custom under which a normative expression is regularly employed - that is, a shared, or "public," use..$^{22}$ Therefore, for Wittgenstein a normative standard and the mode of using it relate to a common practice and so to a wider context than that of the single act by which appealing to a normative standard takes place. Thus, as long as a normative standard maintains a connection with the idea of use, our referring to a normative standard is not only a practice; it is also, and prominently, a public or shared practice.

This understanding finds support in Meredith Williams's discussion of Wittgenstein's treatment of normativity, where she argues that the very idea of normativity requires a socially structured context, namely, a group of individuals who interact. ${ }^{23}$ Related, the notion of a normative standard has a public character as it "presupposes a context of structure, and that is provided by the actual harmonious interactions of a group of people ... that is, the dynamic interactions of a group of people in sustaining certain regularities, customs and patters of actions over time” (Williams 1999, 169). Normative standards, hence, are inescapably embedded in the social fabric: it is the existence of a social practice that provides the necessary framework within which they can be understood and used to guide and justify conduct. Accordingly, on the one hand, normative standards can exist only against the background of a group and a shared, or public, practice; on the other hand, the social and regular use of a normative standard is the necessary context without which the normative standard could not emerge. There is no such thing, in a nutshell, as a normative standard, or any acting on a normative standard, occurring outside a public context. The community, and nothing else, "provides the logical space for an array of alternatives" to which a normative standard can be said to apply. ${ }^{24}$ An individual alone "hasn't the resources for creating the context within which actions can be correct or incorrect” (Williams 1999, 187). In sum, Wittgenstein's remarks legitimise us to conclude that the existence of a normative standard is connected to the regular and public use of a sign and that it makes no sense to conceive of normative standards as considerations existing outside social settings.

This does not entail the claim that a normative standard is what the majority of people think it is, as the community view argues. A community of agents is the context

\footnotetext{
22 This aspect of Wittgenstein's notion of “use” is apparent in Wittgenstein (1968, §§ 49, 199, 206, 240-2; 1978, 334).

${ }^{23}$ See, in particular, Williams (1999, 157-187).

${ }^{24}$ Williams (1999, p. 173). A caveat may be in order here. On this view, there is nothing to prevent isolated individuals from applying a standard, as well as creating new standards: they can do so in virtue of their notional membership of a given community. In other words, living outside society is not a problem so long as the individuals so situated maintain at least an indirect link with this social structure - in the sense that they continue to follow the patterns and the practices learnt and assimilated when they lived in this society.
} 
out of which normative standards can be said to exist; it is not, however, the ultimate measure by which to determine the content of a normative standard, because public use is not the only factor involved in fixing the meaning of a normative standard. As Williams (1999, pp. 176-7; original emphasis) puts it, "we have standards only in virtue of group harmony and against the background of group harmony, but the standards themselves do not refer to, nor are described in terms of, group harmony”. From this view, the community as a whole, namely, the majority of users, has no privileged access to the content of a normative standard. Thus, the bulk of people are just as likely as the single person to misuse a normative standard: there is no such thing as a public or community check on the correct way to go about obeying a normative standard. It may even happen that the entire community is following a normative standard erroneously. This way, the thesis that a practical reason, qua normative standard, has a social nature does not preclude the possibility of a large-scale or even global error in applying normative standards

Importantly, this reading of Wittgenstein's remarks on normativity entails that, qua normative practice, practical justification - the basic idea shaping the notion of a practical reason - has a public character. Within the practical domain a justificatory process does not come to an end when it shows that an action is valued by a specific individual. Justifying a course of conduct requires one to argue that it is acceptable in the light of certain standards that are publicly shared and so can be accepted by anyone who prizes the value that the relevant conduct is functional to: an action is justified as long as it is shown to comply with standards others would also regard as grounded and so is to be acknowledged as worthy of being performed. Insofar as it is located in the normative terrain, accordingly, the justificatory stance cannot be conceptualised without distortion as a stance attached to a particular individual. Quite the contrary, it unavoidably connects with an intersubjective standpoint spanning across, and including, all those who are sensitive to the value of the action one is in the process of justifying. From which it follows that conceptually a practical justification cannot be equated to an essentially personal, intimate, or entirely introspective enterprise. In the practical sphere justifying should, instead, be acknowledged as a necessarily intersubjective practice, namely, a practice consisting in arguing that an action is legitimate in the light of certain shared values.

To rephrase this point, once it is conceived as a normative enterprise, a practical justification has to be regarded as a process consisting in submitting a practical statement to public scrutiny. This is to say that, in order to successfully justify her action, an agent cannot confine herself to showing that she personally likes, desires, or is interested in it. A practical justification cannot be equated, without renouncing its normative status, to an agent's expression of her wishes, inclinations, desires, or interests. Whereas justifying an action may involve some reference to one's wishes, inclinations, desires, motives, and interests, it is not confined, or reducible, to these. Any appeal to a wish, inclination, desire, motives, or interest falls short of a practical justification. Support for this claim is provided by the fact that while wishing, being 
inclined, desiring, having some motive, and taking an interest could be an arbitrary process, practical justifications, qua normative practices, are not. An agent does not need to be accountable for what she wishes, is inclined to, desires, is motivated to, or is interested in. By contrast, justifying an action raises an implicit claim to public accountability, since it is constitutively a non-whimsical activity. This makes justification an enterprise that, by its very constitution, is discontinuous with any purely single-handed effort. Providing a practical justification requires defending the relevant conduct against a shared set of practical standards. A practical justification, in other words, involves submitting an agent's performance to the critical scrutiny of others by making the agent accountable to others as well as to herself for what she does. Practical justification, therefore, is conceptually inseparable from the recognition that there are common practical standards in relation to which one's conduct is assessed and against which the value of that conduct is measured. In other words, justifications are activities that are externally, and so publicly, scrutinisable and checkable. And, this means both acknowledging and committing oneself to constraints that are partially independent of, and not fully relativized to, the individual agent who embarks on the justificatory process.

These remarks have a direct bearing on the nature of a practical reason and also lend support to the publicity thesis. To appreciate this one only has to reconsider the arguments introduced in this section, where I have argued, in a nutshell, that (a) a practical reason is essentially a consideration that justifies; (b) justification, in turn, is conceptually inseparable from the notions of normativity and normative standards; (c) normativity has a social structure; and (d) a normative standard is, as a result, constitutively agent-independent and relational. This means that a practical reason, qua essential component of a justificatory process (a process with a normative nature), is likewise public, or relational, in essence. As long as practical reasons partake of a justificatory dimension and play a normative function in relation to action, they should be regarded as essentially public standards, since practical justification is an activity governed and constrained by intersubjectively acknowledged normative standards. The implication of these remarks is that a practical reason is a relational idea: acting on a reason takes place against the background of a community of agents and cannot be accounted for as an entirely private matter. This is, one may notice, the very idea underpinning the publicity thesis as I interpret it. From the conceptual point of view, then, a practical reason, qua justificatory consideration that partakes of the normative dimension, is an essentially interpersonal standard and, to that extent, is public in its essence.

In conclusion, an agent's reasons do not simply apply to and make claims about that particular agent; they also produce effects on others. The fact that something is a reason for someone to act in a certain way is not a private fact, or a personal affair; it necessarily justifies other individuals' undertakings and so it is essentially public in quality. This means that the justificatory force of a practical reason is transferrable across subjects and their courses of conduct, to the effect that no (genuine) reason for 
action can be equated to an idiosyncratic consideration supporting a particular agent's conduct whilst leaving other subjects completely indifferent. This statement finds support in the view that whereas desires, preferences, inclinations, and interests may only reflect private and personal concerns, a practical reason is by its constitution a public standard - and so a standard other subjects cannot, willingly or unwillingly, abstain from acknowledging.

\section{Conclusions}

In this essay, I took issue with the view that there is a gap setting apart the reasons a single agent may have for doing something and the reasons other agents are bound to acknowledge. This view - which provides the backbones of what is known in the literature as the privacy thesis - is, I have argued, untenable. Practical reasons cannot be presented as personal considerations, understood as purely private concerns justifying an agent's performance of certain courses of action, namely, considerations that in principle can have normative effects on just one agent, or one single group of agents. The authority of a practical reason necessarily travels across agents and impacts on the normative statuses of a potentially indeterminate number of agents. Accordingly, a practical reason should be regarded as public in essence: an agent's recognition of a consideration as a practical reason implies the recognition of its authority by other subjects as well. This is a defining trait of a practical reason, and is thus a characteristic that distinguishes a practical reason from a kind of private cognitive state or volition condition, which, by contrast, may be strictly personal and thus not generalisable, or extendable to other agents. This means that, ultimately, a practical reason individuates a constitutively relational notion. From which it follows that the idea of a practical reason, when understood as referring to a sort of private property of a specific actor, is internally inconsistent and self-contradictory.

The strategy I have used to defend these claims about the publicity of practical reasons has consisted in (a) connecting a reason to the practice of justifying and (b) conceptualising justification as a normative activity. In this way, the claim that normativity is concerned with a necessarily public space - a claim that is paradigmatically defended in Wittgenstein's treatment of normativity - can provide support to the argument that practical reasons, qua considerations with the characteristics of normative standards, require intersubjective exchanges to be established, maintained, modified and extinguished. An agent alone, consequently, does not have the necessary resources to transform a consideration into a reason proper. Practical reasons require a community of agents as a necessary background against which they make sense and are fully intelligible. That is to say, a practical reason is an essentially interpersonal standard, as opposed to a personal concern on which an individual agent acts.

Crucially, the version of the publicity thesis that I have set out to defend in this paper dissolves the alleged gap emerging between the practical reasons an agent has and the practical reasons other agents recognise as valid, whilst at the same time being able to account for the fact that different agents in dissimilar situations may legitimately 
regard diverse performances as justified (which accommodates the widespread belief that certain reasons on which a given agent acts demand from that agent a specific performance that they do not demand of other agents). When the latter is the case, I have argued, it is not because different agents have different reasons - each of which having a private status and so being not recognisable to other agents. It is rather because different agents, whilst appreciating the existence of a public framework of practical reasons and justifications, are, in consideration of their specific positions and peculiar perspectives, legitimated to act on grounds requiring different courses of conduct to them. Accordingly, what is sometimes interpreted as a personal, or agent-relative, reason should in fact be regarded, in the construction set out here, as a consideration that can play a justificatory role for every party involved and yet, by virtue of the context in which it is applied, legitimately demands diverse courses of conduct from different agents. And this means that, if the argument presented in this essay is sound, the fundamental mistake involved in endorsing the privacy thesis rests in interpreting as a conceptual difference - a difference pertaining to the nature, or concept, of a practical reason - what is in fact a merely pragmatic difference - a difference concerning (not what a reason essentially is, but) what a reason may specifically demand from agents who find themselves in different contexts and under different circumstances.

\section{Bibliography}

Anscombe, G. 1985. "Wittgenstein on Rules and Private Language”, Ethics 95, 342352

Baker, G. and P.M.S. Hacker 1984. Scepticism, Rules and Language (Oxford: Blackwell)

Baker, G. and P.M.S. Hacker 1985. Wittgenstein: Rules, Grammar and Necessity. An Analytical Commentary to the 'Philosophical Investigation', Vol. II (Oxford: Blackwell)

Blackburn, S. 1984. “The Individual Strikes Back”, Synthese 58, 281-301

Darwall, S. 1983, Impartial Reason (Ithaca: Cornell University Press)

Dreier, J. 1996. “Accepting Agent Centred Norms” Australasian Journal of Philosophy, 74: 409-422

Gert, J. 2002. "Korsgaard's Private-Reasons Argument”, Philosophy and Phenomenological Research 64, 303-324

Hieronymi, P. 2011. "Reasons for Action”, Proceedings of the Aristotelian Society 111, 407-427.

Korsgaard, C. 1996a. Creating the Kingdom of Ends (Cambridge, Cambridge University Press)

Korsgaard, C. 1996b. The Sources of Normativity (Cambridge, Cambridge University Press)

Korsgaard, C. 2009. Self-Constitution (Oxford, Oxford University Press)

Kripke, S. 1982. Wittgenstein on Rules and Private Language (Oxford: Blackwell) 
LeBar, M. 2001. “Korsgaard, Wittgenstein and the Mafioso”, The Southern Journal of Philosophy 39, 261-271,

Mack, Eric, 1989. “Against Agent-Neutral Value” Reason Papers, 14: 76-85

Mack, Eric, 1998. “Deontic Restrictions are Not Agent-Relative Restrictions.” Social Philosophy and Policy, 15: 61-83

Malcolm, N. 1986. Nothing is Hidden. Wittgenstein's Criticism of His Early Thought (Oxford: Blackwell)

Malcolm, N. 1989. “Wittgenstein's on Language and Rules”, Philosophy 64, 15-28

McDowell, J. 1984. “Wittgenstein on Following a Rule”, Synthese 58, 325-363

McGinn, C. 1984. Wittgenstein on Meaning. An Interpretation and Evaluation (Oxford: Blackwell)

McNaughton D. and P. Rawling. 1991. “Agent-Relativity and the Doing-Happening Distinction”, Philosophical Studies 63, 167-185

McNaughton D. and P. Rawling. 1995. "Value and Agent-Relative Reasons”, Utilitas 7, 31-47

Nagel, T. 1970. The Possibility of Altruism (Princeton: Princeton University Press)

Nagel, T. 1986. The View From Nowhere (New York: Oxford University Press)

Norman, R. 2000. “Public Reason and the 'Private Language’ Argument”, Philosophical Investigations 23, 292-314

O’Day, K. 1998. “Normativity and Interpersonal Reasons”, Ethical Theory and Moral Practice 1, 61-83

Parfit, D., 1984. Reasons and Persons, Oxford: Clarendon Press

Peacocke, C. 1984. "Critical Notice to Wittgenstein on Rules and Private Language”, Philosophical Review 93, 263-271

Pettit, P., 1987. "Universality Without Utilitarianism.” Mind, 72: 74-82

Postema, G. 1998. "Public Reason: An Archeology” in F. D’Agostino and G. Gaus (eds.) Public Reason (Aldershot: Dartmouth), 425-468

Ridge, M. 2005. "Reasons for Action: Agent-Neutral vs. Agent-Relative", The Stanford Encyclopedia of Philosophy (Fall 2008 Edition), E. N. Zalta (ed.), http:// plato.stanford.edu/archives/fall2008/entries/reasons-agent/

Sturgeon, N., 1974. "Altruism, Solipsism, and the Objectivity of Reasons. "Philosophical Review, 83: 374-402

Wallace, J. 2009. “The Publicity of Reasons”, Philosophical Perspectives 23, 471-497

Williams, B. 1981. Moral Luck (Cambridge. Cambridge University Press)

Williams, M. 1999. Wittgenstein, Mind and Meaning (London: Routledge)

Willigenburg, T. 2002. "Shareability and Actual Sharing: Korsgaard's Position on the Publicity of Reasons”, Philosophical Investigations 25, 172-189

Wittgenstein L. 1978. Remarks on the Foundations of Mathematics (Oxford: Blackwell)

Wittgenstein, L. 1968. Philosophical Investigation (Oxford: Blackwell)

Wright, C. 1984. “Kripke’s Account of the Argument against Private Language”, The Journal of Philosophy 81, 759-778 